\title{
Time Series Analysis to Predicting Demand of Roasted Coffee Production
}

\author{
Agatha Rinta Suhardi ${ }^{1}$, Shendy Amalia $^{1}$, Shinta Oktafien ${ }^{1}$, SiskaAyudia Adiyanti $^{1}$, Siti Komariah $^{1} \&$ Titto Rohendra $^{1}$ \\ ${ }^{1}$ Widyatama University, Bandung, Indonesia \\ Correspondence: Agatha Rinta Suhardi, Widyatama University, Cikutra 204 A, 40125, Bandung, Indonesia.
}

Received: April 30, 2019

Accepted: May 30, 2019

Online Published: June 10, 2019

doi:10.5430/ijfr.v10n5p26

URL: https://doi.org/10.5430/ijfr.v10n5p26

\begin{abstract}
Consumer demand conditions for fluctuating roasted coffee and ineffective production planning often lead to excessive production. Excess production will lead to wasteful costs and maintenance of quality on roasted coffee. Production demand forecasting is the basis for making production demand decisions. The purpose of this study is to predict the number of production requests for the next period and determine the most suitable forecasting method in determining the amount of roasted coffee production demand. The object of the data taken is roasted coffee. Analysis methods use moving averages, weighted moving averages, and exponential smoothing. In determining the most suitable forecasting method based on the Mean Absolute Deviation (MAD) forecasting value and the smallest Mean Squared Error (MSE) of each method used. The results of this study indicate that the most suitable forecasting method is using a Weighted Moving Average with a three-month period and forecasting roasted coffee production for November $2016 \mathrm{of} 38.3 \mathrm{~kg}$.
\end{abstract}

Keywords: moving average, weighted moving average, exponential smoothing, forecasting error

\section{Introduction}

The development of free trade between countries has had a considerable influence on the growth of national economic trade, including in the business industry. Increasing effectiveness and efficiency has become the main focus of economic actors so that their businesses can grow and develop from increasingly fierce competitive situations. Currently the coffee business sector has an important role for the economic growth of the people in Indonesia. As a large producer country, coffee exports are the main target for marketing agricultural products in Indonesia with export destination countries. The contribution of coffee exports to the value of exports of agricultural products is quite large, placing Indonesia as the fourth largest coffee exporter in the world. Along with the progress and development of the times, the demand for coffee in the domestic market also shows a tendency to increase coffee consumption.

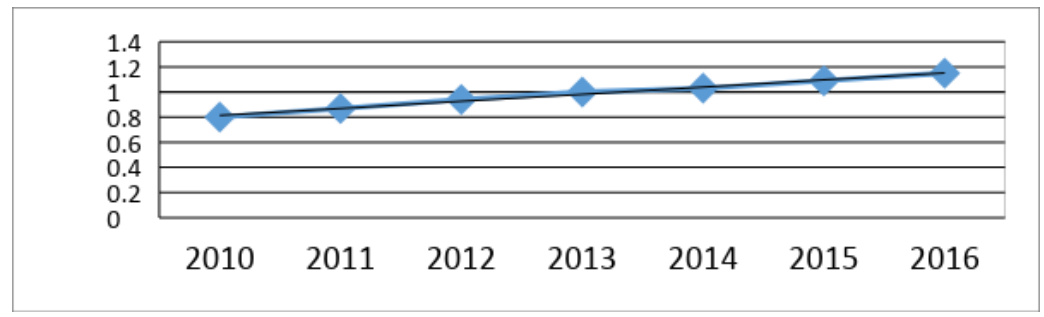

Figure 1. Development of coffee consumption (kg / capita / year)

Source: Association of Indonesian Coffee Exporters and Industries (AEKI) 2015

The increasing trend of coffee consumption in Indonesia is an attractive opportunity for entrepreneurs and companies to enter and invest in coffee industry. In order to meet consumer demand for coffee consumption needs, a company is required to plan all production parameters properly. Effective planning, both in the short and long term, depends on forecasting demand for the company's products.

The company's problem that arises is that it cannot predict the demand for the most produced and highest demand 
roasted coffee production. The amount of production in roasted coffee products is still not efficient because it often leaves excess stock in several periods. During this time, planning the number of production requests made by the company based on experience and policies from the head of the production \& inventory department. In addition to less effective demand planning, another cause of excess production is roasted coffee having a fluctuating demand volume every month. Fluctuating conditions of consumer demand will expose a company to a future filled with uncertainty.

The company chooses several time series forecasting methods including moving average, weight moving average and exponential smoothing in analyzing the amount of forecasting for coffee production demand. Selection of the right forecasting method is done to avoid or minimize the risk of losses that can be experienced by the company. To find the right forecasting method, theforecasting value Mean Absolute Deviation (MAD)andMean Squared Error (MSE) were used for each method used. The selection of the best forecasting method is based on the level of prediction error, where the smaller the level of error produced, the more precise a method in predicting.

\section{Literature Review}

\subsection{Operation Management}

Operation Management is an activity to convert input into output by regulating and coordinating all the resources that are owned effectively and efficiently and then converted into goods or services. The scope of operations management relates to the operation of the operating system, the selection and preparation of the operating system which includes ten decisions, namely the design of goods and services, quality management, process and capacity design, location strategy, spatial strategy, human resources and job design, chain management supply, inventory management, scheduling, maintenance.

Operations of production and operating systems include the preparation of production and operation plans, inventory planning and control and material procurement, maintenance or maintenance of machinery and equipment, quality control, labor management (HR).

\subsection{Forecasting}

Forecasting is an art or science to determine a quantity of one or several products in the coming period through testing data or information in the past. The purpose and function of forecasting is to review the current corporate policies in the past and in the past and see the extent of influence in the future. Good forecasting has several criteria including accuracy, cost, and convenience. There are nine stages in forecasting, namely determining the objectives carried out forecasting, selecting items independent demand to be predicted, determining the time horizon of forecasting, selecting forecasting models, obtaining the data needed to do forecasting, making forecasting, forecasting validation, implementation of forecasting results, monitor the condition of forecasting results. Type of forecasting is economic forecasting, technology forecasting, demand forecasting. While forecasting in the time horizon is divided into short-term forecasting, medium-term forecasting, long-term forecasting.

Forecasting methods there are two approaches or methods, namely qualitative forecasting methods and quantitative forecasting methods. Four Qualitative forecasting methods include Opinions from the Executive Board, Delphi Method, Joint Sales Force, Market Survey. Quantitative forecasting methods can only be used if the availability of information about the past, the existence of information that can be quantified in the form of numerical data, it can be assumed that the past pattern will be sustainable in the future.

\subsection{Time Series}

Methods are methods that analyze a series of data and find patterns of past variations that can be used to estimate future values. The four types of data patterns namely Trend Pattern ( $\mathrm{T}$ ) occur when observational data experiences an increase or decrease over the long term period, Seasonal (S) occurs when a series is influenced by repeated season factors from period to period, Cycle (C) occurs when the data series is affected by long-term economic fluctuations such as those associated with the business cycle. Random $(\mathrm{R})$ occur when observation data fluctuates around the average value of a constant or mean.

The Naive method is a forecasting technique that assumes the forecast demand for the next period is the same as the demand in the previous period. The Nä̈ve method is formulated as:

$$
F_{t}=A_{t-1}
$$

where:

$\mathrm{Ft}=$ the forecast value for the next period

At- $1=$ the actual value of the previous period 
Moving Average is a forecasting method that uses the average of the data actual previous period to forecast the next period. Moving Average is defined as:

$$
F_{t}=\frac{\sum \text { demand in period } n \text { before }}{n}=\frac{A_{t-1}+A_{t-2}+\ldots+A_{t n}}{n}
$$

where:

$\mathrm{Ft}=$ forecast value for the next period

At- $\mathrm{i}=$ actual value of previous period

$\mathrm{n}=$ number of periods used

Weighted Moving Average is a forecasting method that is done by giving weight to the latest period data rather than the weight in the previous period. Weighted Moving Average is formulated as:

$$
F_{t}=\frac{\sum(\text { weight for period } n)(\text { demand in period } n)}{\sum \text { weight }}=\frac{W_{1} A_{t-1}+W_{2} A_{t-2}+\ldots+W_{n} A_{t n}}{W_{1}+W_{2}+\ldots+W_{n}}
$$

where:

$\mathrm{Ft}=$ the forecast value for the next period

At- $i=$ the actual value of the previous period

$\mathrm{Wi}=$ weight value

$\mathrm{n}=$ number of periods used

Exponential Smoothingis a forecasting method of moving average weights with data points weighed by an exponential function. Exponential Smoothing is formulated as:

$$
F_{t}=F_{t-1}+\alpha\left(A_{t-1}-F_{t-1}\right)
$$

where:

$\mathrm{Ft}=$ forecasting value for the next period

Ft-1 $=$ forecasting value for the previous period

At $-1=$ the actual value of the previous period

$\alpha=$ constant $(0<\alpha<1)$

\subsection{Size of Forecasting Accuracy}

Measuring accuracy of forecasting is a way to measure forecasting errors by looking at the suitability of existing data with forecasting data. The way to calculate total forecasting errors, namely:

1. Mean Absolute Deviation (MAD) is the first measure of overall forecasting errors for a model. MAD is formulated as:

$$
M A D=\frac{\sum\left(A_{t}-F_{t}\right)}{n}
$$

where

$\mathrm{Ft}=$ period forecasting value $\mathrm{t}$

$\mathrm{At}=$ actual period value request $\mathrm{t}$

$\mathrm{n}=$ number of periods used

2. Mean Squared Error (MSE) is the average difference in squares between predicted and observed values. MSE is formulated as:

$$
M S E=\frac{\sum\left(A_{t}-F_{t}\right)^{2}}{n}
$$


where:

$\mathrm{Ft}=$ value of period forecasting $\mathrm{t}$

$\mathrm{At}=$ actual demand value of period $\mathrm{t}$

$\mathrm{n}=$ number of periods used by

3. Mean Absolute Percent Error (MAPE) calculated as average absolute differentiation between predicted and actual values, expressed as a percentage of actual value. MAPE is formulated as:

$$
M A P E=\frac{\Sigma \frac{\left(A_{t}-F_{t}\right)}{A_{t}}}{n} \times 100
$$

where:

$\mathrm{Ft}=$ period forecasting value $\mathrm{t}$

$\mathrm{At}=$ actual demand value period $\mathrm{t}$

$\mathrm{n}=$ number of periods used

\section{Research Methodology}

The research method used is descriptive method analysis method used is a method of forecasting time series (timeseries) and a method of measuring the forecasting error. The method is Moving Average, Weighted Moving Average, Exponential Smoothing and Size of Accuracy Forecasting. The variables studied in this research, namely forecasting, with a population of units derived from roasted coffee product sales report for 12 months starting in November 2015 through October 2016. Data collection techniques using interview, observation, and library research.

\section{Results}

Every decision making for the number of production requests in the coming period is still based on intuition, habits and experience of the head of production and inventory, the head of marketing, and the head of finance. The head of the production department always keeps each inventory stock of each roasted coffee product more than 10 to $20 \mathrm{~kg}$. If the stock is below this amount, the company will take action by producing 3-9 $\mathrm{kg}$. The production decision is based on engine capacity and the number of requests or suggestions that come from the marketing and financial departments.

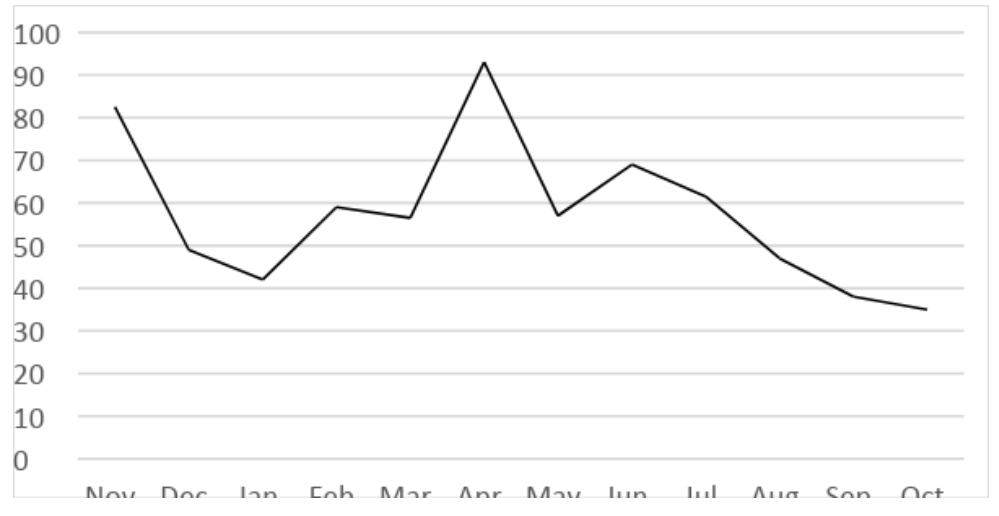

Figure 2. Demand of roasted coffee

Data on roasted coffee demand is processed using the 3-month moving average period forecasting method obtained by MAD value of 13.65 and MSE value of 316.89. While the results of processing using the forecasting method of moving average period of 5 months obtained MAD value of 16.91 and MSE value of 412.22.

Roasted coffee demand data is processed again using the weighted moving average period of 3 months, the weight used is 0.5 for the last month, 0.3 for the past two months, 0.2 for the past three months. The results obtained are MAD 13.59 and MSE 294.01. Then the request data is reprocessed using the weighted moving average period of 5 months, the weight used is 0.3 for the last month, 0.25 for the past two months, 0.2 for the past three months, 0.15 for four months ago, 0.1 for five months ago. The results obtained are MAD values of 16.48 and MSE values of 387.22. 
Data on roasted coffee demand is processed with other forecasting methods, namely by using exponential smoothing using smoothing $(\alpha)$ values of 0.1 and 0.5 . From the results of data processing using exponential smoothing, for the value of $\alpha=0.1$ obtained MAD value of 20.15 and MSE value of 531.71. Whereas for the value of $\alpha=0.5$, the MAD value is 14.4 and the MSE value is 347.26.

From several forecasting methods used above, it can be seen that the weighted moving average period of 3 months for roasted coffee production requests has the smallest MAD and MSE values, namely the MAD value of 13.59 and the MSE value of 294.01.

\section{Discussion}

The company makes production demand decision making using only Opinion from the executive board and market surveys so that the availability of roasted coffee products is always available to meet consumer demand. Every consumer has a different level of needs which will lead to varied and fluctuating demand patterns. Doing production without knowing the pattern of consumer demand will clearly make the company at risk of producing ineffective products. As a result, some processed roasted coffee products are not sold for a long time and eventually become wasted. Losses due to the cost of using raw materials for coffee beans and production machinery such as roasting machines are unavoidable.

The selection of an appropriate forecasting method for roasted coffee production requests is done by comparing the values of MAD and MSE from several methods. Determination of forecasting methods based on the smallest MAD and MSE values. Some methods used include moving averages, weighted moving averages, and exponential smoothing. The most optimal method to be used in predicting the demand for roasted coffee production in the next period is using the weighted moving average period of 3 months. This method is selected based on the MAD value and the smallest MSE value. This MAD value and MSE value represent a picture of data deviation or the difference between the data calculated (predicted) with the actual data. If the value of MAD and the smallest value of MSE means the level of error in the calculation of the data is also the smallest or in other words the weighted moving average period of 3 months is the most accurate forecasting method (close to the actual data).

\section{Conclusion}

Qualitative forecasting methods by using the opinions of the head of marketing, head of finance, and consumer surveys without mathematically and objectively calculating demand forecasting are still not effective enough $[8,9,10,11]$. The forecasting pattern for roasted coffee production demand is a combination of random patterns and trend patterns. The most optimal forecasting method is based on the smallest MAD and MSE results, namely using a weighted moving average with a period of three months because it has the smallest error rate. Forecasting the number of requests for roasted coffee production using the weighted moving average method for November 2016 was $38.3 \mathrm{~kg}$.

\section{References}

Aliyev, A. G., \& Shahverdiyeva, R. O. (2017). Development Problems of Information Provision on the Management of High Technology Park. Journal of Information, 3(1), 1-10. https://doi.org/10.18488/journal.104.2017.31.1.10

Amini, M., Alinezhad, A., \& Najafabadiha, H. (2014). Ranking Iranian Accredited Laboratories with Proficiency Tests Using Promethee Method. Review of Industrial Engineering Letters, 1(1), 25-35. https://doi.org/10.18488/journal.71/2014.1.1/71.1.25.35

Haryono, W. T. (2011). Application of Single Moving Average Method and Exponential Smoothing Method on Forecasting Gray Fabric Products at PT. Standard Textile Printing. Faculty of Economics, SebelasMaret University, Surakarta.

Jonnius, J., \& Auzar, A. (2012). Forecasting Analysis of Company Product Sales (Case Study at PT. SukaFajar Ltd. Bangkinang). Journal of Social and Religious Sciences Research, 5(2), 129-136.

Odhiambo, J. A. (2018). Support Services Available for Kenyan Learners with Cerebral Palsy in Aid of the Performance of Activities of Daily Living. American Journal of Education and Learning, 3(2), 64-71. https://doi.org/10.20448/804.3.2.64.71

Okechukwu, O. C., \& Hyginus, O. O. (2017). National Security and Democratization in Nigeria: The Case of Insurgence. International Journal of Public Policy and Administration Research, 4(1), 12-18. https://doi.org/10.18488/journal.74.2017.41.12.18

Okon, E. O. (2016). Business Development in Nasarawa State: Effect of Poor Sanitation and Waste Management System. International Journal of Economics, Business and Management Studies, 3(1), 36-46. 
Ostertagova, E., \& Ostertag, O. (2012). Forecasting Using Simple Exponential Smoothing Method. Journal of ElectrotechnicaAndInformatica and Sciences, 12(3), 62-66. https://doi.org/10.2478/v10198-012-0034-2

Rakicevic, Z., \& Vujosevic, M. (2015). Focus Forecasting In Supply Chain: The Case Study of Fast Moving Consumer Goods Company in Serbia. Serbian Journal of Management, 10(1), 3-17. https://doi.org/10.5937/sjm10-7075

Sahu, P. K., \& Kumar, R. (2013, August). Forecasting For Sales of Milk Product Demand (Paneer) In Chhattisgarh. International Journal of Inventine Engineering and Sciences, 1(9), 10-13.

Sandy, W. (2018). Factors Influencing Indonesian Students Satisfaction During their Studies in China. Asian Journal of Contemporary Education, 2(2), 136-148. https://doi.org/10.18488/journal.137.2018.22.136.148

Seddighi, H., \& Yoon, I. H. (2018). Stock Market Efficiency and Price Limits: Evidence from Korea's Recent Expansion of Price Limits. Asian Journal of Economics and Empirical Research, 5(2), 191-200. https://doi.org/10.20448/journal.501.2018.52.191.200

Senathip, T., Mujtaba, B. G., \& Cavico, F. J. (2017). Policy-Making Considerations for Ethical and Sustainable Economic Development. Economy, 4(1), 7-14. https://doi.org/10.20448/journal.502.2017.41.7.14

Setiyawati, H., Iskandar, D., \& Basar, Y. S. (2018). The Quality of Financial Reporting through Increasing the Competence of Internal Accountants and Accrual Basis. International Journal of Economics, Business and Management Studies, 5(1), 31-40. https://doi.org/10.20448/802.51.31.39

Shofiana, M. (2015). Application Sales Forecasting for Efficiency of Coffee Bean Inventory Control at UD. Jaya Abadi in Tuban Regency, UIN SunanAmpel Surabaya.

Tanuwijaya, H. (2010). Application of the Winter's Exponential Smoothing Method and the Single Moving Average Method in Hospital Drug Procurement Information Systems. National Technology Management Seminar XI.

Zainudin, Z., Ibrahim, I., Hussain, H. I., \& Hadi, A. R. A. (2017). Debt and Financial Performance of REITs in Malaysia: An Optimal Debt Threshold Analysis. Jurnal Ekonomi Malaysia (Malaysian Journal of Economics), 51(2), 63-74.

Zainudin, Z., Ibrahim, I., Said, R. M., \& Hussain, H. I. (2017). Debt and Financial Performance of REITs in Malaysia: A Moderating Effect of Financial Flexibility. Jurnal Pengurusan (UKM Journal of Management), 50, 3-12. https://doi.org/10.17576/pengurusan-2017-50-01 